DIVISION OF THE HUMANITIES AND SOCIAL SCIENCES

CALIFORNIA INSTITUTE OF TECHNOLOGY

PASADENA, CALIFORNIA 91125

ASYMMETRIES IN EXCHANGE BEHAVIOR INCORRECTLY

INTERPRETED AS EVIDENCE OF PROSPECT THEORY

Charles Plott

California Institute of Technology

Kathryn Zeiler

Georgetown University Law Center

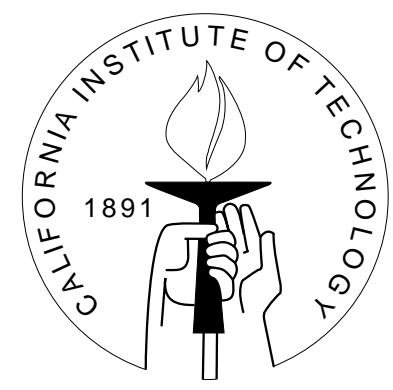

SOCIAL SCIENCE WORKING PAPER 1230 


\title{
Asymmetries in Exchange Behavior Incorrectly Interpreted as Evidence of Prospect Theory
}

\author{
Charles Plott Kathryn Zeiler
}

\begin{abstract}
Systematic asymmetries in exchange behavior have been widely interpreted as support for endowment effect theory, that loss aversion associated with ownership creates an asymmetry in valuations and exchange behavior. According to this theory, which is an application of prospect theory, parting with an endowed object produces a loss that is greater than the gain from acquiring another object of otherwise equal value. The results also have been cited as general support for prospect theory, of which loss aversion is a fundamental component. The experiments reported here suggest that such interpretations of observed exchange asymmetries are incorrect. While exchange asymmetries are readily observable, the data reported here support the claim that measurements of preferences are confounded by experimental procedures. In other words, the data suggest that experimental procedures lead to observed exchange asymmetries. In treatments for which endowment effect theory would predict exchange asymmetries, we observe no asymmetries when we eliminate alternative explanations related to procedures. Therefore, our results do not support the use of observed exchange asymmetries as evidence of loss aversion, endowment effect theory or prospect theory and call into question normative legal analyses grounded in these theories of decision making.
\end{abstract}

JEL classification numbers: C91, K00

Key words: endowment effect, experimental methods, valuation, exchange 


\title{
Asymmetries in Exchange Behavior Incorrectly Interpreted as Evidence of Prospect Theory
}

\author{
Charles R. Plott \\ Kathryn Zeiler*
}

\section{Introduction}

Knetsch (1989) reports an impressive and important discovery. Using a simple experiment, he demonstrated the existence of asymmetries in exchange behavior. ${ }^{1}$ More specifically, when he endowed subjects with coffee mugs and provided each subject an opportunity to exchange the endowed mug for a candy bar, he found that very few subjects wished to give up the endowed mug. By contrast, when a different group of subjects was endowed with candy bars, very few wished to give up the candy bar in exchange for a mug.

Such observed exchange asymmetries have been interpreted in a large and growing literature as support for "endowment effect theory": the notion that loss aversion associated with ownership leads to asymmetries in valuations and exchange behavior. ${ }^{2}$ The theory posits that individuals perceive parting with an endowed good as a loss that is greater than a potential gain from acquiring another good of otherwise equal value (Thaler, 1980). In turn, this interpretation generates support for a specific theory of choice behavior called prospect theory, of which loss aversion is a major component. ${ }^{3}$

\footnotetext{
*Edward S. Harkness Professor of Economics and Political Science, cplott@hss.caltech.edu; Associate Professor of Law, zeiler@law.georgetown.edu; www.georgetown.edu/faculty/kmz3/. The financial support of the National Science Foundation, and the Laboratory of Experimental Economics and Political Science is gratefully acknowledged. We thank Jennifer Arlen, Heidi Li Feldman, Russell Korobkin, Richard Lazarus and Rebecca Tushnet for helpful discussions and comments. In addition, we are grateful for comments provided during presentations of earlier versions of this paper at the Stanford University SITE Conference, the Law and Society Association Annual Meeting, the American Law and Economics Association Annual Meeting and the law schools of Columbia University, Georgetown University, the University of North Carolina - Chapel Hill and the University of Texas - Austin. We are grateful to Kevin Pooler, JD Ellis, Joseph Shifer and Carl Hinneschiedt for excellent research assistance and to several Caltech and Georgetown students who helped us run the experiments.

${ }^{1}$ Knetsch's study was not the first to report asymmetries of this sort (e.g., see Rowe, d'Arge and Brookshire (1980)). It is important to note that the present study's investigation does not address studies that report gaps between willingness to pay and willingness to accept. For a review of these studies see Plott and Zeiler (2005), which reports data supporting the conjecture that observed gaps between willingness to pay and willingness to accept cannot be used to support endowment theory.

${ }^{2}$ Confusion in the literature has emerged due to the language used to describe exchange asymmetries. From the beginning (i.e., Thaler, 1980) the label "endowment effect" commonly has been used to refer to observed asymmetries. Using this label to refer to the observed phenomenon is problematic because it suggests a particular theory as an explanation for asymmetries we refer to as "endowment effect theory." To say that an observed phenomenon demonstrates an endowment effect does not simply mean that an asymmetry was observed, but rather the use of the label directly implies that the observed asymmetry was caused by the influence of ownership on preferences. In some cases throughout this paper we use "endowment effect theory" to distinguish the theoretical explanation from the observed phenomenon, which we refer to as an "exchange asymmetry." See Section 2 for a summary of how the interpretation of observed asymmetries has developed in the literature.

${ }^{3}$ Kahenman and Tversky (1979) developed prospect theory as an alternative to expected utility theory to explain how individuals make decisions under uncertainty. According to prospect theory, preferences are characterized by two fundamental features: (1) reference-point dependence (i.e., gains and losses are
} 
The existence of exchange asymmetries rests on a good empirical foundation and cannot be dismissed. Knetsch's results have been replicated many times. ${ }^{4}$ The experiment's simple design, however, creates an impression that only endowment effect theory can account for observed asymmetries. Indeed, the design's simplicity has led some to question the results of more sophisticated and carefully constructed experiments that do not support endowment effect theory or prospect theory. ${ }^{5}$ The apparent robustness of the results has directed research away from the methods by which choices are elicited and toward a particular theory of preferences and conjectures about how the nature of different goods influences choices. ${ }^{6}$ The results from our study suggest that such diversions are premature.

The experimental results reported here suggest that the interpretation of exchange asymmetries as support for endowment effect theory and prospect theory is misguided. Our results support the conjecture that experimental procedures account for observed asymmetries. We employ several variations of the standard procedures to demonstrate that asymmetries depend strongly on procedures, and that previous measures of exchange asymmetries are likely confounded by phenomena unrelated to loss aversion. Our results demonstrate that, when confounders are eliminated, asymmetries predicted by endowment effect theory disappear.

The paper is organized as follows. Section 2 provides a recap of the design of and results from exchange experiments and provides evidence of the proliferation of the interpretation of exchange asymmetries as support for endowment effect theory in both the economics and law literatures. The prevalence of this particular interpretation prompted our investigation into whether asymmetries in fact support endowment effect theory or whether they result from confounded preference measurements. Section 3 discusses procedures that might confound preference measurements. If endowment effect theory explains observed asymmetries, then the presence of ownership should result in a reluctance to exchange. On the other hand, if observed asymmetries are influenced by factors such as subject perceptions of the nature of the goods, the method by which choices are elicited and the way information is processed then differences in experimental procedures will produce divergent results even when ownership is held constant across designs. Section 4 discusses the basic features and results of the experiments we designed to explore whether procedures confound the measurement of preferences. We first report the results from a pair of experiments designed to investigate whether asymmetries result from confounded preference measurements.

evaluated from some reference point), and (2) loss aversion (i.e., the notion that individuals experience more disutility from losses as they do utility from gains of the same size).

${ }^{4}$ See Section 2 for a summary of the experimental literature.

${ }^{5}$ For example, Korobkin (2003) argues that the endowment effect is probably not the result of a "strategic heuristic" (i.e., a tendency for subjects to revert to basic instincts as sellers (ask high) and buyers (bid low)), a conjecture we investigate in an earlier study (Plott and Zeiler (2005)). To support this claim, Korobkin points to the results from simple exchange experiments similar to those Knetsch (1989) designed. He argues that, if exchange asymmetries are observed even when subjects have no opportunity to ask high as sellers or bid low as buyers, then the "strategic heuristic" probably does not account for the results of experiments in which no gap is observed between willingness to pay and willingness to accept (e.g., Plott and Zeiler (2005)). The results reported in Section 4 call Korobkin's argument into question. ${ }^{6}$ [cites to literature on endowment effects related to money, lotteries, induced-value tokens, mugs, pens, candy bars, environmental goods, etc. including Loomes, Orr and Sugden (2005 working paper); Camerer 2005? The meta study?] 
Next we report the results from two experiments designed to begin investigating the effects and interdependencies of individual design features. The main take-away point is that exchange asymmetries are not robust to changes in the procedures used to observe choices. Ownership is the one feature we hold constant across all experiments; therefore, our results do not support the claim that endowment effect theory explains observed asymmetries. Finally, Section 5 concludes that our results, in combination with results from other studies, ${ }^{7}$ strongly suggest that exchange asymmetries result from confounded preference measurements. As such, our results call into question proposed legal policies that rely on the results of standard "endowment effect" experiments and are therefore grounded in the assumption that individual preferences depend on endowments and that behavior can be explained by prospect theory.

\section{Background}

Knetsch (1989) was the first to report results from exchange experiments, cleverly designed to directly test the reversibility of indifference curves. The experiments involved two groups of subjects. Each subject in the first group was given a coffee mug and then asked to complete a questionnaire. ${ }^{8}$ Following the questionnaire, the subjects were shown candy bars and told that they could each have one in exchange for the mug. The subjects were instructed to hold up a piece of paper with the word "trade" written on it if the candy bar was preferred to the endowed mug. To reduce transaction costs, the experimenter immediately executed all desired trades by taking candy bars to the subjects wishing to exchange. Using a second group of subjects, the same experiment was performed except that each subject in this group was endowed with a candy bar and given an option to trade it for a mug.

The results were quite striking. Of the 76 subjects endowed with mugs, $89 \%$ chose to keep the mug. The possibility that subjects simply preferred the mugs to the candy bars was ruled out by the fact that, of the 87 subjects endowed with candy bars, $90 \%$ chose to keep the endowed candy bar rather than exchange it for a mug. From these results, Knetsch concluded that subjects' choices depended on their endowments. He suggested that the dramatic asymmetry resulted from subjects "[weighing] the loss of giving up their initial reference entitlement far more heavily than the foregone gains of not obtaining the alternative entitlement." In other words, he interpreted the observed behavior as resulting from loss aversion. ${ }^{9}$

Other researchers have obtained similar results using Knetsch's design. Harbaugh et al. (2001) used simple exchange experiments to test whether experience affects the reluctance to trade and found that subjects of different ages with different levels of market experience tend to leave the experiment with the endowed good rather than trading for an alternate good. In addition, List (2003) reports results from exchange experiments also designed to study whether market experience affects exchange

\footnotetext{
${ }_{8}^{7}$ E.g., see Plott and Zeiler (2005).

${ }^{8}$ The questionnaire was devised as an instrument to allow the subjects to a chance to "experience" ownership of the endowed goods for a period of time on the theory that such time would allow them to realize a sense of ownership.

${ }^{9}$ In similar experiments designed to test the assumption of transitivity of preferences, Knetsch (1992 and 1995) obtained nearly identical results. Knetsch (1995) interprets these results as support for loss aversion and prospect theory as well.
} 
asymmetries. He found that subjects with market experience tend not to display exchange asymmetries. For those without market experience, however, he observed a significant asymmetry in choices. ${ }^{10}$ Finally, van Dijk and van Knippenberg (1998) conducted exchange experiments to test the effects of the comparability of consumer goods on the reluctance to trade. Subjects were "rewarded" with a bottle of wine (half one kind and half another) in exchange for participating in the study. Subjects were then allowed to trade with one another. The results suggest that subjects were reluctant to trade in general and were more reluctant to trade when they perceived large differences between the endowed good and the alternate good. ${ }^{11}$

The results from these simple exchange experiments have been interpreted by many as resulting from an endowment effect and loss aversion. Thaler (1980) interprets observed asymmetries from a variety of settings as resulting from loss aversion. Later Kahneman, Knetsch and Thaler (1990) summarize the results reported by Knetsch (1989) and interpret the data as support for endowment effect theory. ${ }^{12}$ They then argue that the data support prospect theory. Guth et al. (1997), ${ }^{13}$ Morrison (1998), ${ }^{14}$ Chapman (1998), ${ }^{15}$ Liberman et al. (1999), ${ }^{16}$ Van Boven et al. (2000), ${ }^{17} \mathrm{Wu}(2001),{ }^{18}$ Mandel

\footnotetext{
${ }^{10}$ In List's experiments, subjects were presented with the endowment first, possessed it while choosing and were gifted it in exchange for completing a questionnaire. The subjects made choices independently of other subjects' choices (i.e., they were approached one at a time) and the procedures did not necessarily suggest anything about the relative value of the goods. List (2004) reports similar results from a study designed to test whether "consumers learn to overcome the endowment effect in situations beyond specific problems they have previously encountered."

${ }^{11}$ Chapman (1998) conducted a similar experiment to test the effects of the likeness of the goods on reluctance to trade. Subjects were randomly endowed with one of four goods and completed a questionnaire while in possession of the endowed good. Whether they were informed of the randomness of the allocation of goods is not clear. They were then asked whether they would be willing to trade it for a similar good and for a dissimilar good. Whether value was suggested by the procedures cannot be determined from Chapman's description of the procedures. Subjects made choices privately using forms. Chapman posited that, if individual preferences depend on endowments, the percentage of subjects willing to trade would be less than $50 \%$. In three of four treatments, the percentage of subjects willing to trade was statistically significantly less than $50 \%$ (at the $1 \%$ level). In a fourth treatment that controlled for transaction costs, however, the percentage of subjects willing to trade in each session was not statistically significantly different from $50 \%$ (at the $5 \%$ level; in the treatments involving dissimilar alternate goods the percentage of subjects willing to trade was less than $50 \%$ at the $10 \%$ level). In fact, in one treatment, Chapman finds a weak "reverse" endowment effect (i.e., of 76 subjects, $59 \%$ traded for a similar good; this percentage is larger than $50 \%$, but only at the $10 \%$ level $(\mathrm{p}=0.06))$.

${ }^{12}$ See also Kahneman et al. (1991).

${ }^{13}$ Guth et al. argue that "effects like the...endowment effect (Knetsch, 1989)... are not easily reconciled with the assumption of individual rationality."

${ }^{14}$ Morrison interprets Knetsch's (1989) observed exchange asymmetries as resulting from an "endowment effect."

${ }^{15}$ Chapman interprets Knetsch's (1989) results as a demonstration of the endowment effect. She goes on argue that "[a] psychological mechanism that can explain reluctance to trade is loss aversion...."

${ }^{16}$ Liberman et al. refer to the results of Knetsch's (1989) study as a "typical demonstration of the endowment effect." They then argue that the "endowment effect has been explained in terms of the general principle of loss aversion," a main feature of prospect theory.

${ }^{17}$ Van Boven et al. cite Knetsch (1989) as support for the claim that "owners value things more than do buyers simply because they own them." They go on to argue that "[t]his endowment effect stems primarily from people's greater sensitivity to losses than to gains: A loss of a given magnitude is more painful than a gain of an equal magnitude is pleasant." In other words, exchange experiment results support the theory of loss aversion.
} 
(2002), ${ }^{19}$ Van Boven et al. (2003), ${ }^{20}$ Tom (2004), ${ }^{21}$ and Huck et al. (2005) ${ }^{22}$ also invoke Knetsch's results as evidence of endowment effect theory, loss aversion and/or prospect theory.

This interpretation of exchange experiment results has bled into legal scholarship as well. In separate experimental literature reviews, Korobkin $(2003)^{23}$ and Rachlinski and Jourden (1998) ${ }^{24}$ refer to Knetsch's (1989) results as evidence of the existence of an endowment effect. Ayres and Vars, ${ }^{25}$ Smith (2000), ${ }^{26}$ Stake (2001), ${ }^{27}$ and Bloche $(2003)^{28}$ also use Knetsch's results as evidence of the existence of an endowment effect (i.e., evidence for endowment effect theory) and/or support for loss aversion and prospect theory. ${ }^{29}$ More importantly, a number of legal commentators advance policy prescriptions that are, in part, responses to the existence of an endowment effect. ${ }^{30}$

Given the prevalence of this particular interpretation of Knetsch's exchange experiment results and its application in normative analyses it is important to determine whether, in fact, it is a correct interpretation. Does endowment effect theory explain exchange asymmetries? Should we attribute this phenomenon to loss aversion and prospect theory? Or, are observed asymmetries unrelated to properties of underlying preferences and simply the result of particular procedures of the experimental design that confound preference measurements? These are the questions we set out to explore here. The next section discusses the procedural issues relevant to our investigation.

\footnotetext{
${ }^{18}$ Wu cites to Kahnemen et al. (1991) and Knetsch (1989) as support for the claim that "[the] notion of 'reference-dependent preferences' has important implications to the study of externalities and the Coase Theorem."

${ }^{19}$ Mendel refers to Knetsch (1989) as support for the claim that "people tend to demand a higher selling price for commodity $\mathrm{x}$ that they own than they would be willing to pay in order to acquire $\mathrm{x}$ as a buyer." He goes on to explain that this phenomenon, known as the endowment effect, "may be viewed as an exemplar of the mere ownership effect in which a target object is rated more favorably by an owner than a non-owner." He then asserts that "[e]xplanations of the endowment effect have tended to rely on psychophysicial notions of reference dependence and loss aversion as postulated in prospect theory...." ${ }^{20}$ Van Boven et al. refer to Knetsch (1989) to support their claim that "[t]he endowment effect...is among the most robust phenomena in the emerging field of behavioral economics."

${ }^{21}$ Tom refers to Knetsch (1989) to support the claim that "the endowment effect is a fundamental characteristic of consumer preference that is... applicable to a variety of consumption goods...."

${ }^{22}$ Huck et al. point to the results reported by Knetsch (1989) to illustrate the claim that "countless experiments" have confirmed early studies providing evidence for the existence of an endowment effect. They go on to argue that the endowment effect "must by now be accepted as a stylized fact."

${ }^{23}$ Korobkin not only analyzes the empirical literature on the endowment effect, but also (rightly) warns about the dangers of formulating normative prescriptions given that the endowment effect seems to be context dependent and economists have not made much headway in determining the causes of exchange asymmetries and gaps between willingness to pay and willingness to accept.

${ }^{24}$ Rachlinski and Jourden refer to Knetsch's (1989) experimental design as one of "several different procedures [used] to demonstrate the endowment effect."

${ }^{25}$ Aryes and Vars cite to Knetsch (1989) as evidence of the formalization of the theory of loss aversion.

${ }^{26}$ Smith interprets the exchange asymmetries reported by Knetsch (1989) as resulting from an endowment effect.

${ }^{27}$ Stake interprets Knetsch's (1989) results as evidence of loss aversion.

${ }^{28}$ Bloche refers to Knetsch (1989) as evidence of the existence of an endowment effect.

${ }^{29}$ Other legal scholars have challenged the existence and stability of the endowment effect. See Curran and Rubin (1995); [Arlen (Vanderbilt paper)?; Arlen, Spitzer and Talley (JLS experimental piece)?].

${ }^{30}$ [add examples here from cites above]
} 


\section{Experimental Procedures under Investigation}

This study focuses on subtle features of experimental procedures used in exchange experiments. In this section we list the experimental procedures we believe are relevant to our investigation and specify our conjectures about why these particular features, as opposed to endowment effect theory, might be responsible for observed asymmetries.

\subsection{Method used to endow subjects}

The specific method used to determine which good to endow to subjects and the language used to convey to subjects the method of determination might influence subject behavior. Specifically, whether subjects acquire the endowed good through some random process or whether they perceive it as being chosen by the experimenter might influence subject choices over goods. According to endowment effect theory, however, the method used to endow subjects is a variable that should have no influence on choices.

While the method used to determine and explain the endowment might influence subject choices in myriad ways unrelated to loss aversion, we offer two specific possibilities. First, the language typically used to convey the nature of the endowment might cause subjects to perceive the endowed good as a gift from the experimenter. For example, imagine that the experimenter, after distributing the endowed good, "X," announces, "X is yours. You own X. I am giving X to you." ${ }^{31}$ Subjects might perceive this language as indicating that $\mathrm{X}$ is a gift from the experimenter, even though the experimenter might simply intend to convey that subjects now own X. Given this perception, subjects might hesitate to trade the "gift" for the alternate good in deference to the experimenter. ${ }^{32}$ In other words, rather than choosing between a simple mug and a simple pen, each subject is choosing between a mug, which was a gift from the experimenter, and a pen.

Second, subjects might perceive the method used to determine and explain the endowment as a signal about the relative value of the goods. ${ }^{33}$ By engaging in particular actions the experimenter might unintentionally reveal what subjects perceive as information about the relative value of the endowment. A subject that is indifferent between the endowed and alternate goods or has not thought much about the relative value of the goods could interpret particular actions as indicating that the experimenter possesses information about the relative value of the goods. A subject who perceives the experimenter as exercising some judgment in determining which good to endow

\footnotetext{
${ }^{31}$ While the exact language used by experimenters in previous experiments is often not reported, the description of the experiments leads one to believe that subjects might have perceived the endowed good as a gift. For example, Knetsch (1989) indicates that "76 were given a coffee mug," and that " 87 participants in the second group were offered an opportunity to make the opposite trade of giving up a candy bar, which had been given to them initially..." (emphasis added).

${ }^{32}$ We thank Richard Lazarus for pointing this out as a potentially important variable related to observed asymmetries.

${ }^{33}$ That subjects gather information by observing the actions of others is well established (e.g., see Plott (2000). Harrison, Harstad and Rutstrom (2004), pp. 128-9, argue that a rational subject who is uncertain about relative value must attempt to infer what he can about it from such cues. Also see Sections 3.2 and 3.3 for additional conjectures about how procedures might signal value to subjects.
} 
reasonably might view the experimenter as having special information about the relative value of the goods.

To eliminate these alternative explanations of observed asymmetries, we employed two different techniques for determining which good to endow. The first technique uses language we suspect encourages the subjects to perceive the endowment as a gift. When the endowed goods were distributed, the experimenter announced, "I'm giving you X. It is a gift. You own it. It is yours." The second technique was designed to convey that the determination of the endowment resulted from a random process - a process through which the experimenter exercised no judgment. Subjects were told that the endowed good was determined by a coin flip before the start of the experiment. ${ }^{34}$ If exchange asymmetries result from the involvement of the experimenter in determining the endowment we should observe an asymmetry when employing the first technique but not the second. If, instead, loss aversion explains observed asymmetries we should observe an asymmetry regardless of the technique employed.

\subsection{Suggestions of Relative Value}

While conducting exchange experiments, experimenters tend to incorporate procedures that allow subjects to realize a sense of ownership vis-a-vis the endowed good prior to asking them to choose one of the goods. For example, subjects often are asked to fill out questionnaires while the endowed good is in front of them. This is thought to provide subjects enough time to develop a sense of ownership (Knetsch, 1989).

A close examination of the procedures, however, reveals that experimenters, intent on emphasizing ownership, might inadvertently signal to the subjects that the endowed good is more valuable than the alternate good. ${ }^{35}$ For example, emphasizing ownership (e.g., "This good is yours. You own it. It belongs to you."), in an attempt to establish a sense of ownership, might signal to the subjects that the endowed good is more valuable than the alternate good. Alternatively, this sort of language might be interpreted as a signal from the experimenter that the "correct" choice is to maintain ownership of the endowed good.

To test whether this feature of the procedures might lead to exchange asymmetries, we altered the standard procedures in two ways. First, when we distributed the endowments, we simply said, "These X's are yours." This is in contrast to emphasizing ownership by saying, "I'm giving you X. It is a gift. You own it. It is yours." Second, the forms subjects used to communicate their choices simply instructed, "Please circle the item you wish to take home with you." The form included three choices: "X," "Y," and "I DON'T CARE." This is in contrast to stating the choices as "I want to keep my $\mathrm{X}$," and "I want to trade my X for a Y." If exchange asymmetries are caused by experimental procedures that suggest relative value, then modifying such procedures potentially will impact choices. On the other hand, if endowment effect theory explains

\footnotetext{
${ }^{34}$ Specifically subjects were told, "Before the start of the experiment, a coin was flipped to determine which good, the mug or the pen, to distribute. It came up heads, which means that we start with the coffee mugs (or pens). The subjects in the other room will start with the pens (or coffee mugs)."

${ }^{35}$ This conjecture is closely related to the conjecture discussed in the immediately preceding section related to possible signals from the experimenter.
} 
exchange asymmetries, then these subtle changes in language should not affect choices, and asymmetries will persist.

\subsection{Location of endowed good at time of choice}

Where the endowed good is located at the time subjects make their choices might influence their decisions. It is important to note that in standard exchange experiments, the experimenter places the endowed good immediately in front of the subjects. As with other procedures analyzed previously, it could be that subjects perceive the position of the endowed good relative to the alternate good as a signal of relative value.

To test whether this feature of the procedures might lead to exchange asymmetries, we altered the standard procedures in a simple way. After presenting subjects with the endowed good and allowing them to inspect it while completing the questionnaires, we replaced the endowed good with the alternate good (reminding subjects that they still owned the endowed good even though it was not sitting in front of them). If exchange asymmetries are caused by signals of relative value produced by the location of the goods, then removing this sort of signal will influence exchange asymmetries (or result in reverse asymmetries). On the other hand, if endowment effect theory explains exchange asymmetries, then this change in procedures should not affect choices, and asymmetries will remain.

We constructed an additional treatment (referred to as the "transaction costs test") to investigate a second conjecture about how the location of the endowed good might influence choices. Specifically, if a subject is indifferent between the endowed good and the alternate good, even a very slight transaction cost (e.g., requiring a subject to raise his hand if he wishes to trade or to take any sort of action to initiate a trade such as the physical exchange of the endowment for the alternate good) might encourage him to keep the good within reach. Indeed, Chapman (1998) speculated that some of her results were due to reluctance to trade because subjects were "truly indifferent between the two items and trading involved transaction costs." Many experimenters (e.g., Knetsch (1989)) design procedures to eliminate (or at least reduce) transaction costs in an attempt to rule them out as a direct cause of observed asymmetries (e.g., hand delivering the alternate good to subjects). The complete removal of transaction costs has proved difficult, however. Few, if any, have been able to conclude definitively that they are not an important driver of observed asymmetries.

We took a different approach to investigate whether transaction costs explain observe asymmetries. We used an approximation of the standard procedures to elicit choices except that we asked subjects to make choices while the alternate good was within their reach. ${ }^{36}$ If subjects are indifferent between the goods and transaction costs make subjects reluctant to trade, then we should observe a "reverse" asymmetry when subjects make choices while the alternate good is in front of them and the endowed good is not. Put simply, transaction costs will result in subjects keeping the alternate good rather than trading back for the endowed good. On the other hand, if endowment

\footnotetext{
${ }^{36}$ See Section 4.2.1 for specific procedures employed in the transaction cost treatment.
} 
effect theory accounts for observed asymmetries, then we should observe subjects trading to retrieve their endowed goods. ${ }^{37}$

\subsection{Public revelation of choices}

Signals as a source of information about value can enter through yet another aspect of the procedures typically employed in studies that report exchange asymmetries. In most reported exchange experiments, including Knetsch's (1989) experiment, subjects are asked to raise their hands if they wish to trade the endowed good for the alternate good. The resulting public revelation of choices might cause a "cascade" of sorts, as those who are contemplating choosing one good might observe, as hands begin to go up or stay down, that most others seem to prefer the other good. ${ }^{38}$ Public revelation of choices might trigger cascades if subjects view other subjects' decisions as signals that provide information about the relative value of the goods. That subjects interpret the choices of others as signals of value is well established. ${ }^{39}$

To control the influence of public revelation of choices on behavior, we used forms to allow subjects to indicate their choices privately. This ensures that subjects' choices

\footnotetext{
${ }^{37}$ Of course it could be that transaction costs and endowment effect theory, in combination with one another, make subjects reluctant to trade. If this is the case, then our results might only provide evidence about which effect overpowers the other in particular contexts.

In a separate test, we investigated whether the order in which the experimenter presents the goods to the subjects matters (see Harrison et al. (2003) for a general discussion of how order effects tend to confound results). We made a simple change to the standard procedures: We presented subjects with the alternate good before presenting them with the endowed good. During these sessions, we distributed mugs to the subjects and informed them that the mugs did not belong to them but that they should inspect them because they would be given an opportunity to obtain one later in the session. We then asked the subjects to complete the questionnaires. After the questionnaires were completed, we removed the mugs and placed them at the front of the room and distributed pens to the subjects. Once each subject possessed a pen the experimenter announced, "These pens are yours." Each student then filled out a form to indicate whether he wanted to keep his pen or trade his pen for a mug. Once the subjects completed the forms by choosing one of the options, the experimenter walked around the room to collect the forms and make any necessary exchanges. We conducted additional sessions using an identical design except that the sessions started with pens rather than mugs.

We collected data from 50 Georgetown University law students. We endowed 17 subjects with mugs and 33 with pens. Seventy-one percent of the mug owners left with mugs and $64 \%$ of the pen owners left with mugs. The proportions are not statistically significantly different $(\mathrm{p}=0.31$; power $=$ 0.0675). This result differs from those obtained using the standard procedures; therefore, it supports the conjecture that order effects might confound preference measurements.

Further investigation is required, however, to better understand this result. In this experiment forms were used to collect choices rather than raised hands. Therefore, we cannot infer that order alone caused the disparate results. As a general matter, we have only limited notions about the independent contribution of various aspects of procedures. Thus, we chose to conserve our research budget and subject pool and not attempt to isolate all the possible effects of individual procedures and how they might interaction with one another. While these preliminary results suggest that it is reasonable to infer that the order of presentation at least contributes to the disappearance of asymmetries, further study of these feature and additional data are necessary to better understand the nature of this phenomenon.

${ }^{38}$ In an early pilot we encountered just this sort of behavior. Subjects reported to us after the experiment that they were using raised hands as an indication of the relative value of the goods and that this influenced their decisions. We also noticed this phenomenon time and time again in later experiments in which we collected choices using raised hands and directly observed the sequences in which the hands were raised. See Table 2 for a breakdown of the data by session.

${ }^{39}$ See Anderson and Holt (1977); Hung and Plott (2001).
} 
are independent of other subjects' choices. If exchange asymmetries are due to the public nature of choice elicitation, then allowing subjects to communicate their decisions privately should eliminate them. On the other hand, if endowment effect theory explains asymmetries, then the elicitation mechanism should not significantly influence the results.

The following section provides details on the exact procedures we used to elicit choices in four exchange experiments that implement various sets of the procedures discussed in this section. In addition, we provide results from each treatment.

\section{Experiment Designs and Results}

To explore the influences of different sets of procedures we employed various designs that incorporate different combinations of the procedures. Clearly we have not offered a formal theory of exactly how all aspects of individual procedures might influence choices. Indeed, different procedures might interact through the same vehicle, such as signaling, or procedures might confound an effect by reinforcing the influences of a particular signal. Given this possibility our research strategy is not to identify the influence of each procedure that we might imagine but instead operate through collections of procedures. In this manner we can explore the impact of procedures generally without analyzing their particular aspects in great detail. Of course we have an interest in the contribution of individual procedures or particular aspects of individual procedures, and the design does provide some such focus, but understanding the microstructure of each procedure's contribution is not required to conclude that procedures as a whole (as opposed to an endowment effect) are responsible for exchange asymmetries.

The first pair of results demonstrates that procedures dramatically affect choices. From this we conclude that the procedures, and not endowment effect theory, account for observed exchange asymmetries. The second set of results, which represents the first step of an investigation of individual procedures and possible interactions between them, provides insights into which procedures (or combinations of procedures) seem to be driving differences in elicited choices. The features of each design are summarized in Table $1 .{ }^{40}$ We drew our subjects from pools of Caltech students and Georgetown Law students (see Table 2 for details).

\subsection{Asymmetries Depend Strongly on Procedures}

To test for whether elicitation procedures affect subject choices, we conducted two treatments. The first treatment, which we use as a baseline, contains none of the controls we identified as important for proper preference measurements. The second incorporates controls meant to eliminate possible confounders of preference measurement. The data support the conjecture that observed exchange asymmetries result from confounded preference measurements. Specifically, we observed a significant exchange asymmetry when no controls are employed. When we control for confounders, however, the asymmetry disappears.

\subsubsection{A Baseline}

\footnotetext{
${ }^{40}$ Table 2 provides details regarding each session conducted including the date, person(s) who ran the experiment, the subject pool and the goods used. We also summarize the results for each session individually in Table 2 .
} 
We first elicited choices using a set of baseline procedures that have many similarities with procedures used in the literature. We call this the "baseline" rather than a "replication" because the exact procedures used in earlier studies are not always clearly specified in the literature. This baseline allows us to identify controls that eliminate confounders of preference measurements.

We distributed coffee mugs branded with university insignia to the subjects (Caltech mugs to Caltech students and Georgetown mugs to Georgetown students) and informed the subjects that they owned the mugs by announcing, "I'm giving you the mug. It is a gift. You own it. It is yours." ${ }^{41}$ While the endowed goods were located in front of the subjects, we allowed them approximately three minutes to fill out questionnaires. ${ }^{42}$ After they completed the questionnaires, we allowed them to pass a few pens around the room so they could inspect them. ${ }^{43}$ Once each subject had an opportunity to inspect a pen the experimenter instructed, "Please raise your hand if you want to keep the mug, the thing you own, rather than trading it for a pen." 44 The experimenter then walked around the room to make any necessary exchanges. We conducted additional sessions using an identical design except that subjects were endowed with pens instead of mugs.

We collected data from 129 Georgetown University law students and Caltech students. We endowed 64 subjects with mugs and 65 with pens. Eighty-four percent of the mug owners left with mugs and $28 \%$ of the pen owners left with mugs. A twosample, one-tailed test of equality of proportions supports a rejection of the null hypothesis that the percentages are identical in favor of the alternative hypothesis that the percentage of mug owners that left with mugs is greater than the percentage of pen owners that left with mugs $(\mathrm{p}=0.00)$. In other words, these data reveal a statistically significant exchange asymmetry.

\subsubsection{Full Set of Controls}

Next we modified the procedures to test for whether particular procedures lead to exchange asymmetries. We began these sessions by informing the subjects that mugs and pens would be used during the experiment. Subjects were then told that a coin was flipped before the start of the experiment to determine which good, the mug or the pen, would be distributed first. We then distributed mugs to the subjects and announced, "These coffee mugs are yours." Next, we asked the subjects to complete the

\footnotetext{
${ }^{41}$ We obtained the coffee mugs from campus bookstores for roughly $\$ 5$ apiece. We removed the price tags from all goods prior to conducting the sessions.

${ }^{42}$ Appendix A contains a typical questionnaire. Subjects' answers to the questions were irrelevant to our study. We employed the questionnaires so that our results would be comparable to previously reported results. Each session lasted for less than ten minutes and subjects possessed the endowed good for roughly three to five minutes before making their choices. This is roughly the same amount of time provided in other experiments of this kind.

${ }^{43}$ The pens, which were labeled with the name of the subjects' university, were also obtained from campus bookstores for approximately $\$ 5$ apiece. In one session we used candy bars that were not labeled with the name of the university but cost roughly the same as the other goods.

${ }^{44}$ The standard procedures ask subjects to raise their hands if they want to trade the endowed good for the alternate good. We altered this feature of the standard procedures to test our conjecture that public choices lead to cascades. If the lack of controls in this design encourages subjects to keep the endowed good, the subjects will tend to raise their hands. If our cascades conjecture is correct (see Section 3.4 supra), subjects will tend to go along with the perceived majority. It seems reasonable to assume that a majority with raised hands is easier to detect than a majority that remains with hands down.
} 
questionnaires. After the questionnaires were completed, we took the mugs from the subjects, placed them at the front of the room and distributed pens to the subjects. After providing time to inspect the pens, we asked each subject to decide which good to keep and to indicate the decision on a form. ${ }^{45}$ The forms simply indicated the options and did not re-emphasize the fact that subjects owned one of the goods. Once each subject completed a form, the experimenter walked around the room to collect them and make any necessary exchanges. We conducted additional sessions using an identical design except that subjects owned pens rather than mugs.

In Table 1 we report the features of and results from this treatment. We collected data from 139 Georgetown University law students (see Table 2 for session details); 69 were endowed with mugs and 70 were endowed with pens. Fifty-four percent of the mug owners left with mugs and $67 \%$ of the pen owners left with mugs. A two-sample, one-tailed test of equality of proportions supports the hypothesis that the percentages are identical $(p=0.95) .{ }^{46}$ In other words, we observed no exchange asymmetry of the expected sort under this set of procedures. Indeed, we observe a (somewhat weak) reverse asymmetry. ${ }^{47}$

These results, taken together, support the conjecture that exchange asymmetries result from experimental procedures and cannot be explained by endowment effect theory or prospect theory. The next section reports results of the beginnings of an exploration of the effects of specific procedures and how procedures interact with one another.

\subsection{Initial Tests of Specific Procedures and Their Interactions}

Without a clear theory of the mechanisms through which procedures influence choice it is almost futile to study the effects of individual procedures on choices. Despite this, using key procedures as cornerstones we begin an investigation into the effects of specific procedures and how procedures interact with one another. This section reports the design features of these treatments and their results. ${ }^{48}$

\subsubsection{Transaction Cost Test}

The transaction cost test was designed to explore whether transaction costs might explain observed asymmetries. We distributed coffee mugs to the subjects and informed them that they owned the mugs. While the endowed good was located in front of them, subjects spent approximately three minutes filling out questionnaires. After they completed the questionnaires, we removed the endowed mugs and placed the mugs at

\footnotetext{
${ }^{45}$ See Appendix C for a sample of the forms used during these sessions. Subjects were given an opportunity to indicate indifference between the goods by circling the option "DON'T CARE." None of the subjects asked which good would be received upon choosing this option. Each subject who chose "DON'T CARE" received the good in her possession at the time she completed the form. Only 17 of the 139 subjects reported indifference; therefore, the results from statistical tests of differences of proportions are virtually identical when we include and exclude these data.

${ }^{46}$ We tested the null hypothesis of equality against an alternative hypothesis that the percentage of mug owners that left with mugs was greater than the percentage of pen owners that left with mugs.

${ }^{47}$ When the alternative hypothesis is framed as "the percentage of pen owners that left with mugs is greater than the percentage of mug owners that left with mugs," a two-sample test of equality of proportions results in a p-value of 0.06 .

${ }^{48}$ To be clear, this set of experiments represents only the beginnings of the construction of a more complete set of experiments that one might use to explore more thoroughly the design issues we identify. The complete set, however, is outside the scope of this study.
} 
the front of the room (reminding them that they still owned them) and passed around pens for their inspection. Each student then filled out a form to indicate whether he wanted to keep his mug or trade his mug for a pen. ${ }^{49}$ Once the subjects completed the forms by choosing one of the options, the experimenter walked around the room to collect the forms and make any necessary exchanges. We conducted additional sessions using an identical design except that subjects were endowed with pens instead of mugs.

We collected data from 101 Georgetown University law students and Caltech students (see Table 2 for session details). We endowed 53 subjects with mugs and 48 with pens. Seventy-two percent of the mug owners left with mugs and $50 \%$ of the pen owners left with mugs. A two-sample, one-tailed test of equality of proportions supports a rejection of the null hypothesis that the percentages are identical in favor of the alternative hypothesis that the percentage of mug owners that left with mugs is greater than the percentage of pen owners that left with mugs $(p=0.01)$. In other words, these data reveal a statistically significant exchange asymmetry.

This result suggests that transaction costs do not drive observed exchange asymmetries. In addition, when combined with the results from the treatment employing a full set of controls (see Section 4.1.2), this result suggests that other modifications of the standard procedures (e.g., removing the experimenter from the determination of the endowment, etc.) possibly account for the elimination of exchange asymmetries in that particular treatment. ${ }^{50}$ Further study is required to better understand these results.

\subsubsection{Standard Procedures}

This design tests for possible effects of changing the meaning of raised hands during the choice phase of the experiment. This design is identical to the baseline design except that a raised hand indicates that the subject desires to trade the endowed good for the alternate good rather than keeping it. ${ }^{51}$ By altering the design in this way, we attempt to gain insight into what sorts of signals subjects send to one another when they make public choices and how these signals interact with other procedures.

In Table 1 we report the features of and results from this treatment. We collected data from 96 Georgetown University law students (see Table 2 for session details). We endowed 44 subjects with mugs and 52 with pens. Seventy-seven percent of the mug owners left with mugs and $62 \%$ of the pen owners left with mugs. A two-sample, onetailed test of equality of proportions (somewhat weakly) supports a rejection of the null hypothesis that the percentages are identical in favor of the alternative hypothesis that the percentage of mug owners that left with mugs is greater than the percentage of pen owners that left with mugs $(\mathrm{p}=0.06)$. In other words, we observed an exchange

\footnotetext{
${ }^{49}$ Appendix B contains the form the subjects used to communicate their decisions.

${ }^{50}$ It also suggests that the results obtained when implementing the full set of controls are not driven by the fact that the endowed good is not in front of the subjects when they are choosing between the two goods.

${ }_{51}$ Of all the designs we study, the "standard procedures" design seems most similar to Knetsch's (1989) procedures (hence the label). Note one important possible exception, however. Knetsch (1989) does not make clear the exact language used to convey ownership to the subjects. Therefore, our language (i.e., "I'm giving you the mug. It is a gift. You own it. It is yours.") might not mirror the language Knetsch used.
} 
asymmetry. ${ }^{52}$ That the result from this treatment differs from the result of the baseline design indicates that choices are sensitive to subtle changes in the experiment design.

In sum, it is important to stress that any inferences about how particular features of the procedures affect choices are mere conjectures at this stage. Given our results, we suspect that interaction effects exist between various procedures and the information contained in Table 1 is insufficient to understand them. Understanding the interaction effects between procedures, however, could be useful in constructing a theory that explains and predicts behavior in exchange experiments (and more broadly). ${ }^{53}$ This study represents the first attempt to understand how procedures influence whether exchange asymmetries are observed. Further research is necessary to understand more fully the interaction effects between the procedures.

\section{Discussion and Conclusions}

Observed exchange asymmetries have been advanced as support for special theories about the basic principles underlying preferences and valuation (e.g., valuations depend on ownership status); therefore, Knetsch's (1989) discovery should not be dismissed. The experiments we report, along with those reported by others, however, suggest that the procedures used in the experiments have a systematic influence on the patterns of observed choices. Such data stimulate questions about the precise connections between procedures and choices. Our thesis is that the nature of the connection goes beyond the basic elements of endowment effect theory and prospect theory and to the procedures themselves.

Our empirical results suggest that either no "endowment effect" of the sort predicted by prospect theory exists or the effect is sufficiently weak that other phenomena easily swamp it. If asymmetries of observed choices are to be interpreted as strong evidence about the principles that operate when individuals make choices, then such asymmetries should be robust against subtle features of procedures and variations in the set of procedures used to conduct experiments. While we suspect that a general theory about perception and related features of decision processes might explain observed asymmetries we hasten to note that this sort of explanation is unrelated to any theory about the particular shapes of preferences. The asymmetries exhibited in exchange experiments do not seem to be sufficiently robust to support loss aversion and prospect theory as a foundation for normative claims regarding policy and law. More research, however, is needed to determine the precise connections between procedures and choices.

\footnotetext{
52 This result is not as strong as Knetsch's original result (see Section 2, supra). Our study does not provide enough information, however, to speculate about which features of the design might be driving the disparity in results.

${ }^{53}$ Harrison, Harstad and Rutstrom (2004) begin some steps in this direction.
} 


\section{References}

Anderson, L.R. and C.A. Holt. 1977. Information Cascades in the Laboratory. American Economic Review 87(5):847-862.

Aryes, I. and F.E. Vars. 1998. When Does Private Discrimination Justify Public Affirmative Action? Columbia Law Review 98:1577-1641.

Bloche, M.G. 2003. The Invention of Health Law. California Law Review 91:247-322.

Curran, C. and P.H. Rubin. 1995. The Endowment Effect and Income Transfers. Research in Law and Economics 17:207-217.

Guth, W., J.P. Krahnen and C. Rieck. 1997. Financial Markets with Asymmetric Information: A Pilot Study Focusing on Insider Advantages. Journal of Economic Psychology 18:235-257.

Harbaugh, W.T., K. Krause and L. Vesterlund. 2001. Are Adults Better Behaved Than Children? Age, Experience and the Endowment Effect. Economic Letters 70:175-181.

Harrison, G.W., R. M. Harstad and E.E. Rutström. 2004. Experimental Methods and Elicitation of Values. Experimental Economics 7:123-140.

Harrison, G.W., E. Johnson, M.M. McInnes and E.E. Rutström. 2003. Risk Aversion and Incentive Effects: Comment. Working Paper.

Huck, S., G. Kirchsteiger and J. Oechssler. 2005. Learning to Like What you HaveExplaining the Endowment Effect. The Economic Journal 115:689-702.

Hung, A.A. and C.R. Plott. 2001. Information Cascades: Replication and an Extension to Majority Rule and Conformity-Rewarding Institutions. American Economic Review 91(5):1508-1520.

Johnson, J.G. and J.R. Busemeyer. A Dynamic, Stochastic, Computational Model of Preference Reversal Phenomena. Psychological Review (forthcoming).

Kahneman, D., J.L. Knetsch and R.H. Thaler. 1990. Experimental Tests of the Endowment Effect and the Coase Theorem. Journal of Political Economy 98(6):13251348 .

. 1991. The Endowment Effect, Loss

Aversion, and Status Quo Bias. Journal of Economic Perspectives 5:193-206.

Kahneman, D. and A. Tversky. 1979. Prospect Theory: An Analysis of Decision Under Risk. Econometrica 47:263-291. 
Kahneman, D. and A. Tversky. 2000. Choices, Values, and Frames. Cambridge: Cambridge University Press.

Knetsch, J.L. 1989. The Endowment Effect and Evidence of Nonreversible Indifference Curves. American Economic Review 79(5):1277-1284.

. 1992. Preferences and Nonreversibility of Indifference Curves. Journal of Economic Behavior and Organization 17:131-139.

. 1995. Asymmetric Valuation of Gains and Losses and Preference Order Assumptions. Economic Inquiry 33(1):134-141.

Korobkin, R. 2003. The Endowment Effect and Legal Analysis. Northwestern University Law Review 97:1227-1293.

Liberman, N., L.C. Idson, C.J. Camacho and E.T. Higgins. 1999. Promotion and Prevention Choices Between Stability and Change. Journal of Personality and Social Psychology 77(6):1135-1145.

List, J. 2003. Does Market Experience Eliminate Market Anomalies? Quarterly Journal of Economics 118(1):41-71.

Plott, C.R. 2000. Markets as Information Gathering Tools. Southern Economic Journal 67(1):2-15.

Plott, C.R. and K. Zeiler. 2005. The Willingness to Pay-Willingness to Accept Gap, the "Endowment Effect," Subject Misconceptions and Experimental Procedures for Eliciting Valuations. American Economic Review 95(3): xx.

Rachlinski, J.J. and F. Jourden. 1998. Remedies and the Psychology of Ownership. Vanderbilt Law Review 51:1541-1582.

Rowe, R., R. d'Arge and D.S. Brookshire. 1980. An Experiment in the Value of Visibility. Journal of Environmental Economics and Management 7:1-19.

Smith, H.E. 2000. Ambiguous Quality Changes from Taxes and Legal Rules. University of Chicago Law Review 67:647-723.

Stake, J.E. 2001. The Uneasy Case for Adverse Possession. Georgetown Law Journal 89:2419-2474.

Thaler, R. 1980. Toward a Positive Theory of Consumer Choice. Journal of Economic Behavior and Organization 1:39-60.

Tom, G. 2004. The Endowment-Institutional Affinity Effect. The Journal of Psychology 138(2):160-170. 
Van Boven, L., D. Dunning and G. Loewenstein. 2000. Egocentric Empathy Gaps Between Owners and Buyers: Misperceptions of the Endowment Effect. Journal of Personality and Social Psychology 79(1):66-76.

Van Boven, L., G. Loewenstein and D. Dunning. 2003. Mispredicting the Endowment Effect: Underestimation of Owners' Selling Prices by Buyer's Agents. Journal of Economic Behavior \& Organization 51:351-365.

van Dijk, E. and D. van Knippenberg. 1998. Trading Wine: On the Endowment Effect, Loss Aversion, and the Comparability of Consumer Goods. Journal of Economic Psychology 19:485-495.

Wu, S. 2001. Adapting to Heart Conditions: A Test of the Hedonic Treadmill. Journal of Health Economics 20:495-508. 
Table 1: Design Features and Continuum of Results (from no asymmetry to significant asymmetry)

\begin{tabular}{|c|c|c|c|c|}
\hline & $\begin{array}{l}\text { Full Set of } \\
\text { Procedural } \\
\text { Controls }\end{array}$ & $\begin{array}{l}\text { Standard } \\
\text { Procedures }\end{array}$ & $\begin{array}{c}\text { Transaction } \\
\text { Costs Test }\end{array}$ & $\begin{array}{l}\text { Baseline } \\
\text { Procedures }\end{array}$ \\
\hline $\begin{array}{l}\text { Endowed good } \\
\text { immediately in } \\
\text { front of subject at } \\
\text { time of choice }\end{array}$ & NO & YES & NO & YES \\
\hline $\begin{array}{l}\text { Experimenter } \\
\text { chose and gave } \\
\text { OR randomly } \\
\text { assigned which } \\
\text { good to endow }\end{array}$ & $\begin{array}{l}\text { RANDOMLY } \\
\text { ASSIGNED }\end{array}$ & $\begin{array}{l}\text { EXPERIMENTER } \\
\text { CHOSE AND GAVE }\end{array}$ & $\begin{array}{l}\text { EXPERIMENTER } \\
\text { CHOSE AND GAVE }\end{array}$ & $\begin{array}{l}\text { EXPERIMENTER } \\
\text { CHOSE AND GAVE }\end{array}$ \\
\hline $\begin{array}{l}\text { Experimenter } \\
\text { purposefully and } \\
\text { repeatedly } \\
\text { emphasized } \\
\text { ownership }\end{array}$ & NO & YES & YES & YES \\
\hline $\begin{array}{l}\text { Choices made by } \\
\text { public show of } \\
\text { hands OR use of } \\
\text { private forms }\end{array}$ & FORMS & $\begin{array}{c}\text { HANDS } \\
\text { (TRADE } \\
\text { ENDOWED GOOD) }\end{array}$ & FORMS & $\begin{array}{c}\text { HANDS } \\
\text { (KEEP ENDOWED } \\
\text { GOOD) }\end{array}$ \\
\hline $\begin{array}{c}\text { (\# mug owners, \# } \\
\text { pen owners) }\end{array}$ & $(69,70)$ & $(44,52)$ & $(53,48)$ & $(64,65)$ \\
\hline $\begin{array}{l}\text { (\% mug owners } \\
\text { that left with } \\
\text { mugs, \% pen } \\
\text { owners that left } \\
\text { with mugs) }\end{array}$ & $\begin{array}{l}(54 \%, 67 \%) \\
\text { diff }=-13 \%\end{array}$ & $\begin{array}{c}(77 \%, 62 \%) \\
\text { diff }=15 \%\end{array}$ & $\begin{array}{l}(72 \%, 50 \%) \\
\text { Diff }=22 \%\end{array}$ & $\begin{array}{c}(84 \%, 28 \%) \\
\text { diff }=56 \%\end{array}$ \\
\hline Result $^{\dagger}$ & $\mathrm{p}=0.94^{\ddagger}$ & $P=0.06$ & $\mathrm{p}=0.01$ & $p=0.00$ \\
\hline
\end{tabular}

The bolded entries indicate the particular controls in place for each treatment.

Overall, we observed a general preference for the mug. Of the 531 subjects that participated (including pilots), 330 (or $62 \%)$ left with mugs. This is statistically significantly greater than $50 \%(p=0.00)$. This general mug preference, however, does not affect our results as we measured asymmetries by comparing the percentage of mug owners that left with mugs and the percentage of alternate good owners that left with mugs. This measurement controls for the overall mug preference.

${ }^{\dagger}$ Results are from two-sample tests of equality of proportions (null hypothesis: proportions are equal; alternative hypothesis: \% mug owners that left with mugs $>\%$ of pen owners that left with mugs).

ॠ If we use an alternative hypothesis of $\mathrm{H}_{\mathrm{a}}$ : \% of mugs owners that left with mugs $<\%$ of pen owners that left with mugs, the $\mathrm{p}$ value is equal to 0.06 . This (weakly) supports a hypothesis that a "reverse" asymmetry exists. 
Table 2: Summary of Sessions

\begin{tabular}{|c|c|c|c|c|c|}
\hline & Date & Experimenter & Subject Pool & $\begin{array}{l}\text { \# mug owners / } \\
\text { \# left with mug }\end{array}$ & $\begin{array}{l}\text { \# alt. good* owners / \# left } \\
\text { with mug }\end{array}$ \\
\hline & & & & & \\
\hline \multirow{3}{*}{$\begin{array}{c}\text { Transaction } \\
\text { Costs Test }\end{array}$} & Jun 403 & Zeiler & Caltech UG & $\begin{array}{l}28 / 19 \\
(68 \%)\end{array}$ & $\begin{array}{l}28 / 14 \\
(50 \%)\end{array}$ \\
\hline & Jun 8 and 1003 & Zeiler & Gtown JD & $\begin{array}{l}13 / 10 \\
(77 \%)\end{array}$ & $\begin{array}{l}10 / 5 \\
(50 \%)\end{array}$ \\
\hline & Jun 2504 & Zeiler & Gtown JD & $\begin{array}{l}12 / 9 \\
(75 \%)\end{array}$ & $\begin{array}{l}10 / 5 \\
(50 \%)\end{array}$ \\
\hline & & & & & \\
\hline \multirow{9}{*}{$\begin{array}{l}\text { Full Set of } \\
\text { Procedural } \\
\text { Controls }\end{array}$} & Jul 1404 & Zeiler & Gtown JD & $\begin{array}{c}8 / 5[1]^{* *} \\
(63 \%)\end{array}$ & $\begin{array}{c}9 / 5[1] \\
(56 \%)\end{array}$ \\
\hline & Jul 1504 & Zeiler & Gtown JD & $\begin{array}{c}6 / 4[1] \\
(67 \%)\end{array}$ & $\begin{array}{c}7 / 4[1] \\
(57 \%)\end{array}$ \\
\hline & Jul 2604 & RAs & Gtown JD & $\begin{array}{c}10 / 6[1] \\
(60 \%)\end{array}$ & $\begin{array}{l}5 / 2[1] \\
(40 \%)\end{array}$ \\
\hline & Jul 2704 & RAs & Gtown JD & $\begin{array}{c}5 / 4[1] \\
(80 \%)\end{array}$ & $\begin{array}{c}5 / 4[0] \\
(80 \%)\end{array}$ \\
\hline & Aug 0304 & RAs & Gtown JD & $\begin{array}{c}9 / 1[1] \\
(11 \%)\end{array}$ & $\begin{array}{c}18 / 12[1] \\
(67 \%)\end{array}$ \\
\hline & Sept 2004 & Zeiler & Gtown JD & $\begin{array}{c}17 / 8[3] \\
(47 \%)\end{array}$ & $\begin{array}{c}14 / 11[1] \\
(79 \%)\end{array}$ \\
\hline & June 2105 & Zeiler and RA & Gtown JD & $\begin{array}{c}4 / 2[1] \\
(50 \%)\end{array}$ & N/A \\
\hline & June 2305 & Zeiler and RA & Gtown JD & $\begin{array}{c}5 / 2[0] \\
(40 \%)\end{array}$ & $\begin{array}{c}8 / 6[2] \\
(75 \%)\end{array}$ \\
\hline & June 2705 & Zeiler and RA & Gtown JD & $\begin{array}{l}5 / 5[0] \\
(100 \%)\end{array}$ & $\begin{array}{c}4 / 3[1] \\
(75 \%)\end{array}$ \\
\hline \multirow{8}{*}{$\begin{array}{l}\text { Baseline } \\
\text { Procedures }\end{array}$} & Aug 2004 & Plott and RA & Caltech & $\begin{array}{c}9 / 7 \\
(78 \%) \\
\end{array}$ & $\begin{array}{c}8 / 2 \\
(25 \%) \\
\end{array}$ \\
\hline & Aug 1804 & Plott & Caltech & $\begin{array}{l}7 / 5 \\
(71 \%)\end{array}$ & $\mathrm{N} / \mathrm{A}$ \\
\hline & Sept 904 & $\begin{array}{l}\text { Zeiler and faculty } \\
\text { assistant }\end{array}$ & Gtown JD & $\begin{array}{l}17 / 14 \\
(82 \%)\end{array}$ & $\begin{array}{l}17 / 3 \\
(18 \%)\end{array}$ \\
\hline & April 2605 & Zeiler and RA & Gtown JD & $\begin{array}{c}8 / 7 \\
(88 \%)\end{array}$ & $\begin{array}{l}15 / 6 \\
(40 \%)\end{array}$ \\
\hline & June 1705 & Zeiler and RAs & Gtown JD & $\begin{array}{c}8 / 8 \\
(100 \%)\end{array}$ & $\begin{array}{l}7 / 2 \\
(29 \%)\end{array}$ \\
\hline & June 2905 & Zeiler and RA & Gtown JD & $\begin{array}{c}8 / 7 \\
(88 \%)\end{array}$ & $\begin{array}{c}8 / 2 \\
(25 \%)\end{array}$ \\
\hline & July 1005 & Zeiler and RA & Gtown JD & $\mathrm{N} / \mathrm{A}$ & $\begin{array}{l}10 / 3 \\
(30 \%) \\
\end{array}$ \\
\hline & July 1105 & Zeiler and RA & Gtown JD & $\begin{array}{c}7 / 6 \\
(86 \%)\end{array}$ & N/A \\
\hline \multirow{3}{*}{$\begin{array}{c}\text { Standard } \\
\text { Procedures }\end{array}$} & Sept 0104 & Zeiler and RA & Gtown JD & $\begin{array}{l}15 / 12 \\
(80 \%)\end{array}$ & $\begin{array}{c}30 / 18 \\
(60 \%)\end{array}$ \\
\hline & April 1405 & $\begin{array}{l}\text { Zeiler and faculty } \\
\text { assistant }\end{array}$ & Gtown JD & $\begin{array}{c}9 / 6 \\
(67 \%)\end{array}$ & $\begin{array}{l}11 / 9 \\
(82 \%)\end{array}$ \\
\hline & June 3005 & Zeiler and RAs & Gtown JD & $\begin{array}{l}20 / 16 \\
(80 \%)\end{array}$ & $\begin{array}{l}11 / 5 \\
(45 \%)\end{array}$ \\
\hline
\end{tabular}

* In each session except for the first session conducted on June 4, 2004, we used pens as the alternate good. During the first session we used candy bars.

** The numbers enclosed in square brackets indicate the number of subjects who reported being indifferent between the two goods by circling "DON'T CARE" on the decision record. See Appendix C for form used during sessions. 


\section{Appendix A: A Sample Questionnaire}

1. The current U.S. Secretary of State is

How likely is it that your answer is correct?

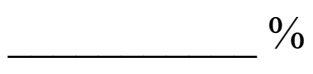

(enter a likelihood between $0 \%$ and 100\%)

2. Bucharest is the capital city of

How likely is it that your answer is correct? $\%$ (enter a likelihood between $0 \%$ and 100\%)

3. The author of the novel The Phantom of the Opera is

How likely is it that your answe $\%$ (enter a likelihood between $0 \%$ and 100\%)

4. The actor plays the U.S. President on the TV series The West Wing.

How likely is it that your answer is correct? (enter a likelihood between $0 \%$ and 100\%)

5. What does the acronym NASA stand for?

How likely is it that your answer is correct? $\%$ (enter a likelihood between $0 \%$ and 100\%) 
Appendix B: Sample Transaction Records for Transaction Cost Test

\section{Transaction Record}

$\square \quad$ I want to keep my mug.

$\square \quad$ I want to trade my mug for a pen.

This form was used in sessions in which we endowed subjects with mugs. Subjects were asked to check one box.

\section{Transaction Record}

$\square \quad$ I want to keep my pen.

$\square \quad$ I want to trade my pen for a mug.

This form was used in sessions in which we endowed subjects with pens. 
Appendix C: Sample Decision Record for Sessions Using Full Set of Procedural Controls

\section{DECISION RECORD}

Please circle the item you wish to take home with you.

MUG

PEN

DON'T CARE 